\title{
Probing of Interaction between Alogliptin Benzoate and Human Serum Albumin Using Multi-Spectral Methods and Molecule Docking Technique
}

\author{
Nan Zhang, Jianbo Chen*, Zhuowei Han \\ College of Life Science, Shanghai Normal University, Shanghai, China \\ Email: ^jianboch@shnu.edu.cn
}

How to cite this paper: Zhang, N., Chen, J.B. and Han, Z.W. (2021) Probing of Interaction between Alogliptin Benzoate and Human Serum Albumin Using MultiSpectral Methods and Molecule Docking Technique. Open Access Library Journal, 8: e7283.

https://doi.org/10.4236/oalib.1107283

Received: March 4, 2021

Accepted: May 25, 2021

Published: May 28, 2021

Copyright $\odot 2021$ by author(s) and Open Access Library Inc.

This work is licensed under the Creative Commons Attribution International License (CC BY 4.0).

http://creativecommons.org/licenses/by/4.0/

\section{(c) (i) Open Access}

\begin{abstract}
The interaction of alogliptin benzoate with human serum albumin had been characterized under physiological conditions using multi-spectral methods and molecular docking technique. The work presented in this paper focused on the interaction mechanism, the conformational changes of HSA and the binding sites of alogliptin benzoate with human serum albumin. The binding distance, binding constants, the number of binding sites and the binding forces had been investigated through fluorescence and spectral overlaps. Results indicated the presence of static quenching between alogliptin benzoate and human serum albumin. Moreover, the van der Waals forces and hydrogen bonding drove the binding process. The analysis results of UV-vis absorption spectroscopy, synchronous fluorescence spectrometry, circular dichroism spectroscopy and three-dimensional fluorescence spectroscopy revealed that alogliptin benzoate changed the conformation of human serum albumin. In addition, molecule docking and competitive experimental results suggested the binding sites located at IIA subdomain of human serum albumin. This research is vital to providing reference for studying the pharmacodynamics and pharmacokinetics mechanisms of alogliptin benzoate.
\end{abstract}

\section{Subject Areas}

Biochemistry

\section{Keywords}

Alogliptin Benzoate, Human Serum Albumin, Interaction, Spectroscopic Techniques, Molecular Docking 


\section{Introduction}

Diabetes mellitus is a multifactorial metabolic disease with insulin resistance and hyperglycemia. Hitherto, diabetes and its complications have seriously threatened human health [1] [2]. There are numerous antidiabetic drugs such as antidiabetic sulfonylureas, thiazolidinediones, biguanides, and dipeptidyl-peptidase IV (DPP-4) inhibitors [3]. By comparison, DPP-4 inhibitors increase the active level of incretin hormones, thus better regulating blood glucose levels and alleviating hypoglycemia. Based on the excellent effect, the action mechanism of DPP-4 inhibitors has been revealed. Glucagon-like peptide-1 (GLP-1) and glucose-dependent insulinotropic polypeptide (GIP) are incretin hormones. They potentiate glucose-induces insulin secretion [4]. DPP-4, a kind of serine protease on the cell surface, can disintegrate GLP-1 and GIP to disrupt glycometabolism. DPP-4 inhibitors delay the degradation of GLP-1 and GIP, so as to regulate blood glucose level of patients with diabetes mellitus type 2 [5].

Human serum albumin (HSA) is a single-chain protein composed of 585 amino acids. It accounts for around $60 \%$ in plasma with a molecular weight of about $67 \mathrm{kDa}$. As the major delivery protein in vivo, it transports endogenous and exogenous substances to target organs or tissues. In addition, it has three identical domains (I, II and III) with two subdomains (A and B), which are able to combine with drugs and other small molecules [6] [7] [8].

Recently, more and more studies focused on the interaction of drugs and HSA. Eraj revealed the presence of hydrophobic and hydrogen bonds between synthesis of copper (II) complexes and HAS [9]. Hekmat confirmed that paclitaxel combined with nano-diamond particles can form a complex with HAS [10]. The interaction between drugs with HSA is quite attention-getting because of its clinical and pharmaceutical importance. It affects the transportation and elimination of drugs in vivo, as well as the pharmacokinetics and pharmacodynamics properties of drugs. As a specific sort of DPP-4 inhibitors, alogliptin benzoate (ALTB) is well known for its better regulation of blood glucose levels and alleviation of hypoglycemia with glucose dependence mechanism, while its interaction mechanism with HSA has not been reported yet. In this study, the interaction of ALTB with HSA was investigated by fluorescent spectrometry, spectral overlaps, UV-vis absorption spectroscopy, synchronous fluorescence spectrometry, circular dichroism (CD) spectrometry, three-dimensional fluorescence spectroscopy, molecule docking and competitive experiments. The interaction mechanism and the effects of ALTB on the conformational changes of HSA were demonstrated in this paper.

\section{Materials and Methods}

\subsection{Materials}

HSA and ALTB were purchased from Shanghai yuanye Bio-Technology Co., Ltd (with 98\% purity). Ultrapure water was used throughout the experiments. All other reagents were of analytical grade and used without further purification. 
ALTB was dissolved in methyl alcohol (guarantee reagent) with a concentration of $1.0 \times 10^{-3} \mathrm{~mol} / \mathrm{L}$. HSA stock solution was prepared in Tris-HCl buffer solution with a concentration of $1.0 \times 10^{-4} \mathrm{~mol} / \mathrm{L}$. All solutions were stored at below $4^{\circ} \mathrm{C}$ before experiments.

\subsection{Methods}

The UV-vis absorption spectra and the CD spectra measurements had been carried out from $200 \mathrm{~nm}$ to $350 \mathrm{~nm}$. The fluorescence spectra were scanned from $300 \mathrm{~nm}$ to $500 \mathrm{~nm}$ at excitation wavelength of $280 \mathrm{~nm}$. Synchronous fluorescence spectra were scanned from $200 \mathrm{~nm}$ to $350 \mathrm{~nm}$ with the $\Delta \lambda$ values of $15 \mathrm{~nm}$ for tyrosine (Tyr) and $60 \mathrm{~nm}$ for tryptophan (Trp). Through setting the firing interval as $5 \mathrm{~nm}$, three-dimensional fluorescence spectra were scanned with excitation wavelength from $200 \mathrm{~nm}$ to $350 \mathrm{~nm}$, emission wavelength from $200 \mathrm{~nm}$ to $500 \mathrm{~nm}$. All the emission and excitation slits were $5 \mathrm{~nm}$. Autodock 2.5 was used for molecule docking. The crystal structure of HSA (PDB ID: 1H9Z) was obtained from protein database (PDB).

\section{Results and Discussion}

\subsection{Interaction Mechanism Analysis}

\subsubsection{Fluorescence Quenching Experiments}

It is reported that the fluorescence spectroscopy provides information on the binding mechanism of ligand to fluorophore [11]. The fluorescence spectra of HSA scanned in the presence of increasing concentrations of ALTB were shown in Figure 1. Results reflected that the addition of ALTB decreased the intrinsic fluorescence of HSA. It indicated that ALTB could interact with HSA by quenching its intrinsic fluorescence [12].

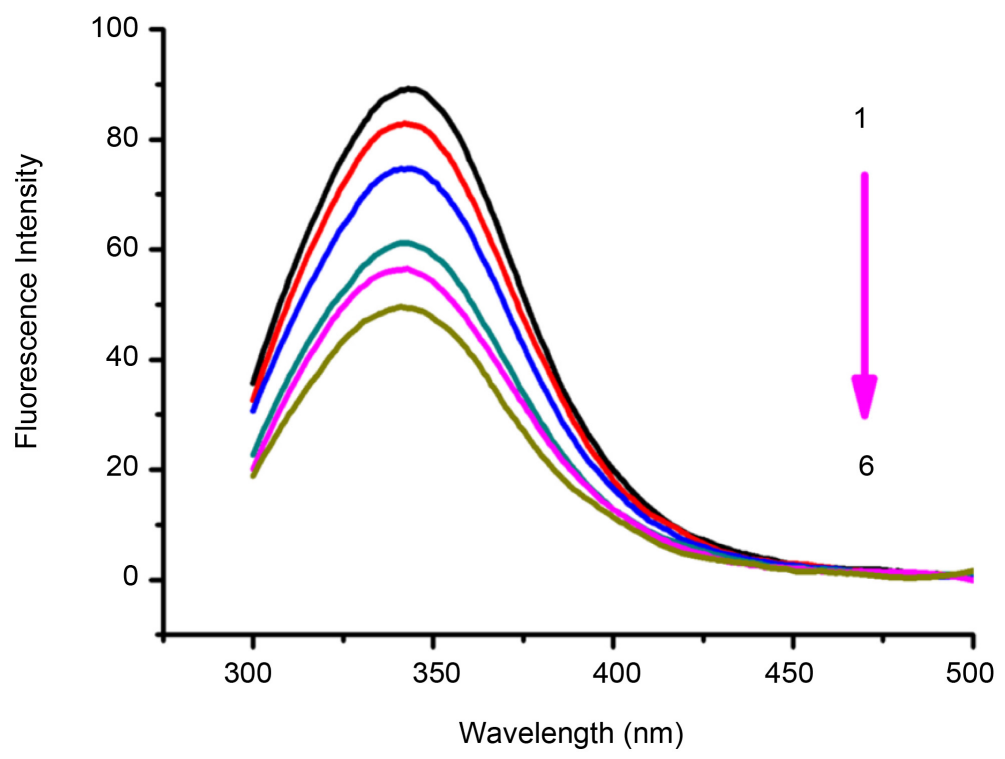

Figure 1. Effects of ALTB on fluorescence emission spectra of HSA. (1) $C_{(\mathrm{HSA})}=$ $1 \times 10^{-6} \mathrm{~mol} / \mathrm{L},(2-6) C_{(\mathrm{ALTB})} / C_{(\mathrm{HSA})}=5,10,15,20,25 . T=298 \mathrm{~K}, \mathrm{pH}=7.4$. 
The quenching mechanism is usually classified as static quenching and dynamic quenching [13]. The dynamic quenching depends on the diffusion of quencher to fluorophore, while the static quenching arises from the forming of the ground-state complex between fluorophore and quencher. They can be distinguished by the values of biomolecular quenching rate constant $\left(K_{q}\right)$ and Stern-Volmer quenching constant $\left(K_{S V}\right)$ at different temperatures. Higher temperature leads to larger values of $K_{q}$ and $K_{S V}$ for dynamic quenching, while it tends to result in smaller values of $K_{q}$ and $K_{S V}$ for static quenching. In addition, the maximal value of $K_{q}$ had been reported approximately $2.0 \times 10^{10} \mathrm{~L} \cdot \mathrm{mol}^{-1} \cdot \mathrm{s}^{-1}$ for dynamic mechanism [14]. In order to investigate the quenching mechanism of ALTB with HSA, the quenching constants calculated through the following equation (Equation) had been displayed in Table 1

$$
F_{0} / F=1+K_{q} \tau_{0}[Q]=1+K_{s v}[Q]
$$

$F_{0}$ and $F$ represent the fluorescence intensity of HSA in the absence and presence of ALTB at concentration $[Q]$, respectively. $[Q]$ is the concentration of ALTB. " $\tau_{0}$ " is the average lifetime of fluorophore without quencher, which is usually $1.0 \times 10^{-8} \mathrm{~s}$ for HSA [15].

$K_{S V}$ and $K_{q}$ were obtained from the slopes of linear regressions exhibited in Figure 2. The values of $K_{S V}$ and $K_{q}$ decreased with the increase of temperatures in Table 1. Furthermore, the values of $K_{q}$ were much larger than $2.0 \times 10^{10}$ $\mathrm{L} \cdot \mathrm{mol}^{-1} \cdot \mathrm{s}^{-1}$. These results revealed that ALTB statically quenched the fluorescence of HSA.

Table 1. Quenching constants and binding parameters of ALTB-HSA system.

\begin{tabular}{rcccc}
\hline$T / \mathrm{K}$ & $K_{S V}\left(10^{4} \mathrm{~L} \cdot \mathrm{mol}^{-1}\right)$ & $K_{q}\left(10^{12} \mathrm{~L} \cdot \mathrm{mol}^{-1} \cdot \mathrm{s}^{-1}\right)$ & $K_{\mathrm{a}} /\left(\mathrm{L} \cdot \mathrm{mol}^{-1}\right)$ & $n$ \\
\hline $298 \mathrm{~K}$ & 3.39 & 3.39 & $1.34 \times 10^{6}$ & 1.35 \\
$303 \mathrm{~K}$ & 3.05 & 3.05 & $3.41 \times 10^{5}$ & 1.22 \\
$308 \mathrm{~K}$ & 2.72 & 2.72 & $1.70 \times 10^{4}$ & 0.96 \\
\hline
\end{tabular}

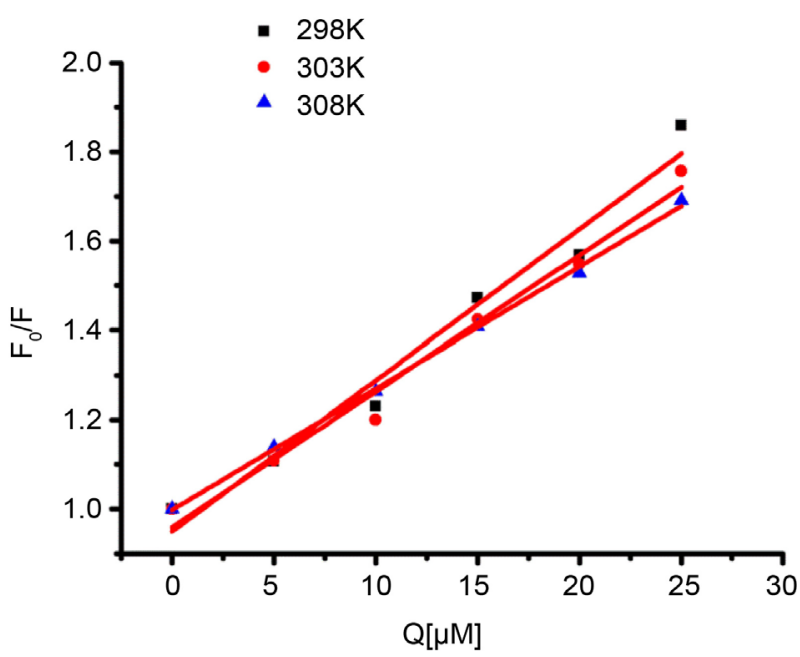

Figure 2. Stern-volmer plots of ALTB-HSA system. 


\subsubsection{Binding Constants and the Number of Binding Sites}

The binding constants had been calculated by Equation (2) and results are displayed in Table 1.

$$
\log \left[\left(F_{0}-F\right) / F\right]=\log K_{a}+n \log [Q]
$$

$K_{a}$ is the binding constants. The $n$ is the number of binding sites. The slopes and intercepts exhibited in Figure 3 determined the values of $n$ and $K_{a}$. The binding constants decreased as the temperature goes up. It suggested the reduction in the stability of the ground-state complex and hence the existence of static quenching mechanism. In addition, the values of $\mathrm{n}$ are approximately 1 , which revealed the presence of the single binding site between ALTB and HSA [16].

\subsubsection{Thermodynamic Analysis for Binding Forces}

The thermodynamic parameters had been calculated by Equations (3)-(5) and results are shown in Table 2 [17] [18].

$$
\begin{gathered}
\ln K=-\Delta H / R T+\Delta S / R \\
\Delta G=\Delta H-T \Delta S \\
\Delta G=-R T \ln K
\end{gathered}
$$

$K$ is the binding constant. $R$ is the gas constant. $T$ is the corresponding thermodynamic temperature. $\Delta G, \Delta H$ and $\Delta S$ are the changes of free energy, enthalpy and entropy, respectively. The negative values of $\Delta G$ indicated the binding process of ALTB with HSA was spontaneously. As for negative values of $\Delta H$

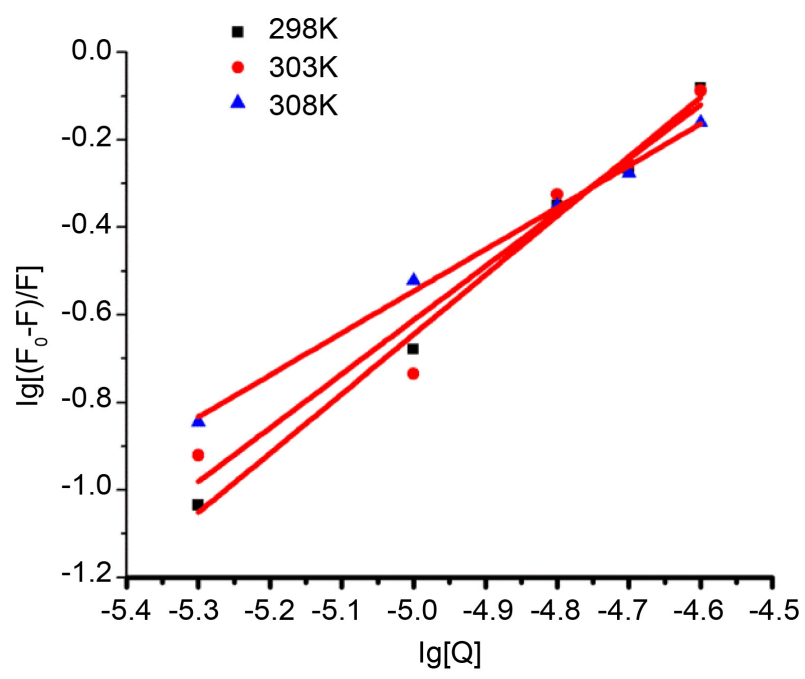

Figure 3. Double logarithm plots of ALTB-HSA system.

Table 2. Thermodynamic parameters of ALTB-HSA system at different temperatures.

\begin{tabular}{cccc}
\hline$T / \mathrm{K}$ & $\Delta G /\left(\mathrm{KJ} \cdot \mathrm{mol}^{-1}\right)$ & $\Delta H /\left(\mathrm{KJ} \cdot \mathrm{mol}^{-1}\right)$ & $\Delta S /\left(\mathrm{KJ} \cdot \mathrm{mol}^{-1} \cdot \mathrm{k}^{-1}\right)$ \\
\hline $298 \mathrm{~K}$ & -34.954 & & -0.999 \\
$303 \mathrm{~K}$ & -32.092 & -332.535 & -0.992 \\
$308 \mathrm{~K}$ & -24.943 & & -0.999 \\
\hline
\end{tabular}


and $\Delta S$, it implied van der Waals forces and hydrogen bonding drove the binding process [19].

\subsubsection{Energy Transfer and Binding Distance}

According to Forster non-radiative energy transfer theory, the energy transfer efficiency requires not only enough spectral overlaps, but also a binding distance shorter than $8 \mathrm{~nm}$ [20].

Figure 4 is the overlaps of the emission spectrum of HSA with the absorption spectrum of ALTB. The binding distance $(r)$ can be calculated by Equation (6).

$$
E=1-\frac{F}{F_{0}}=\frac{R_{0}^{6}}{R_{0}^{6}+r^{6}}
$$

$E$ is the transfer efficiency. $F_{0}$ and $F$ are the fluorescence intensity of HSA in the absence and presence of ALTB, respectively. $R_{0}$ is the critical distance when the value of $E$ is $50 \%$ [21], the calculation of which is achieved by Equation (7).

$$
R_{0}^{6}=8.8 \times 10^{-25} K^{2} n^{-4} \Phi J
$$

$K^{2}$ is the spatial orientation factor of the dipole. The $n$ is the refractive index of the medium. The $\Phi$ is the fluorescence quantum yield. $J$ represents the overlap integral of the absorption spectrum of ALTB and the fluorescence emission spectrum of HSA. The $J$ can be calculated through Equation (8).

$$
J=\frac{\sum F(\lambda) \varepsilon(\lambda) \lambda^{4} \Delta \lambda}{\sum F(\lambda) \Delta \lambda}
$$

$F(\lambda)$ and $\varepsilon(\lambda)$ reflect the fluorescence intensity of HSA and the absorption coefficient of ALTB at the wavelength $\lambda$, respectively. According to Equations (6)-(8), it can be calculated that $J=1.69 \times 10^{-14} \mathrm{~cm}^{3} \cdot \mathrm{L} \cdot \mathrm{mol}^{-1}, E=0.126, R_{0}=2.72$ $\mathrm{nm}$ and $r=3.76 \mathrm{~nm}$. The values of $r$ indicated that HSA and ALTB were close to each other. A strong bind exists between ALTB and HSA. Moreover, the presence

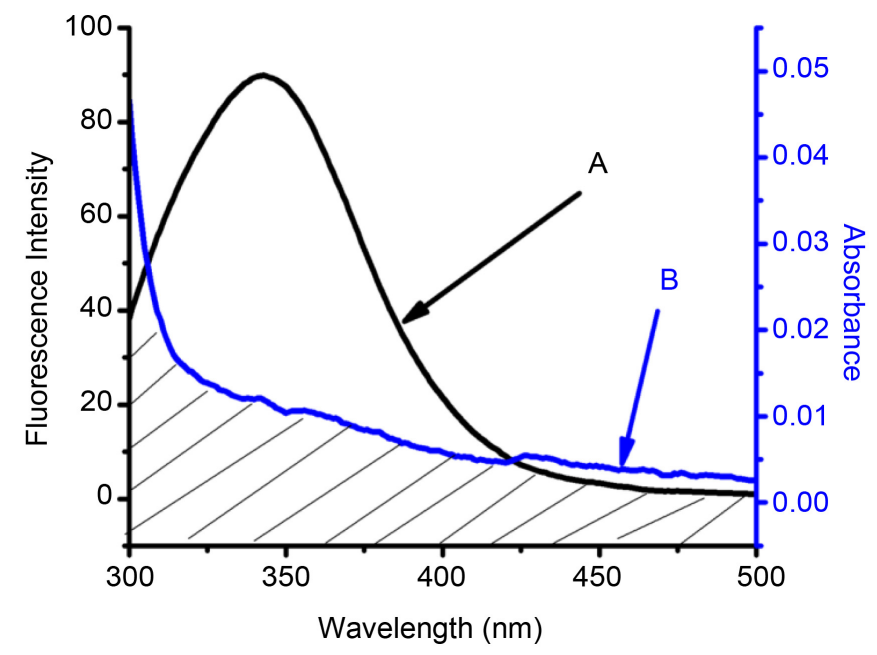

Figure 4. Overlaps of the fluorescence spectrum of HSA (A) with the absorbance spectrum of $\operatorname{ALTB}(\mathrm{B}), C_{(\mathrm{HSA})}=C_{(\mathrm{ALTB})}=1 \times 10^{-6}$ $\mathrm{mol} / \mathrm{L}$. 
of energy transformation from HSA to ALTB gets proved [19]. And the larger value of $r$ compared to $R_{0}$ also revealed the presence of static quenching mechanism of ALTB with HSA [22] [23].

\subsection{Conformational Investigations}

\subsubsection{UV-Vis Absorption Spectra}

For static fluorescence quenching, changes in UV-vis absorption spectroscopy arise from the formation of the complex. In this section, UV-vis absorption spectroscopy is applied to explore changes of conformation of HSA and the formation of ALTB-HSA complex [24] [25]. HSA embraces two characteristic absorption peaks due to the transition of valence electrons. The strong absorption peak at $210 \mathrm{~nm}$ (Peak 1) exhibits the characteristic of peptide bond. The weak absorption peak at $280 \mathrm{~nm}$ (Peak 2) is related to conjugated double bonds in Tyr, Trp [26] [27]. Figure 5 is the UV-vis absorption spectra of ALTB-HSA system. With the addition of ALTB, obvious increments in absorbance peaks show up, thus indicating the formation of ALTB-HSA complex and the changing conformation of HSA [28] [29].

\subsubsection{Synchronous Fluorescence Spectra}

The endogenous fluorescence of HSA comes from Tyr, Trp and phenylalanine (Phe) residues [30]. The synchronous fluorescence spectroscopy is widely used to explore the changes of the microenvironment and the solvent polarity of the fluorophore molecules (HSA) [31]. $\Delta \lambda$ is the wavelength intervals between excitation and emission wavelengths. When $\Delta \lambda$ are stabilized at 15 or $60 \mathrm{~nm}$, the synchronous fluorescence provides the characteristic information of Tyr or Trp residues, separately [32]. The shifts of maximum emission wavelength affect the hydrophobicity and the polarity of HSA. The red shift reflects a higher polarity and a lower hydrophobicity of HSA [23] [20]. The synchronous fluorescence

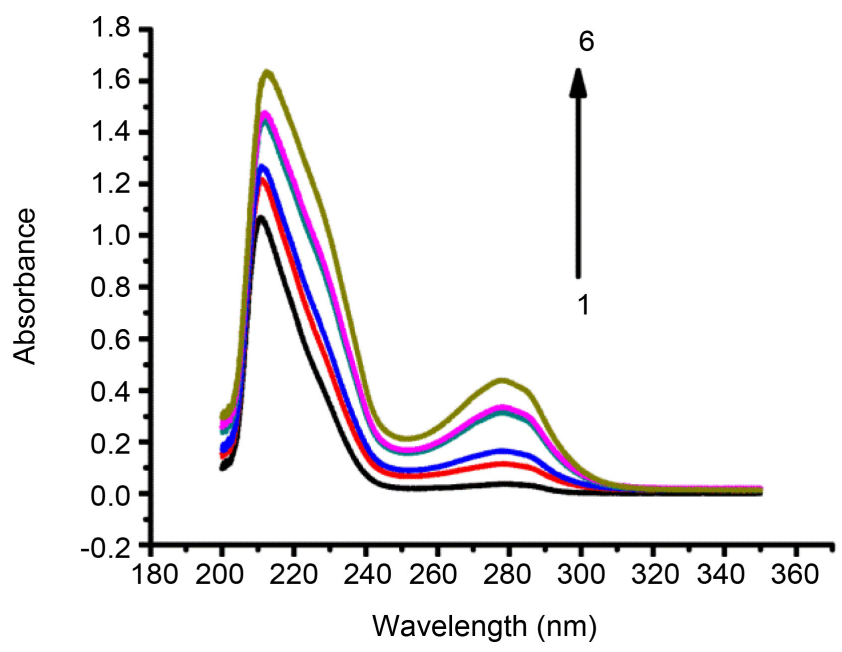

Figure 5. UV-vis absorption spectra of ALTB-HSA system. (1) $C_{(\mathrm{HSA})}=1 \times 10^{-6} \mathrm{~mol} / \mathrm{L},(2-6) C_{(\mathrm{ALTB})} / C_{(\mathrm{HSA})}=5,10,15,20,25 . T=$ $298 \mathrm{~K}, \mathrm{pH}=7.4$. 
spectra of HSA-ALTB system were shown in Figure 6. As the concentration of ALTB increased, the fluorescence intensities of HSA decreased accompanied by the red shifts. It implied that ALTB increased the polarity and decreased the hydrophobicity around Tyr and Trp.

\subsubsection{Spectra}

CD signal is sensitive to investigate the secondary structure of HSA. HSA has two negative bands at $208 \mathrm{~nm}$ and $222 \mathrm{~nm}$, respectively [33] [34]. These two negative bands are the characteristic peaks of $\alpha$-helix of HSA. The CD spectra of HSA-ALTB system were shown in Figure 7. The content of a-helix increased from $47.63 \%$ to $54.33 \%$ with the addition of ALTB. It revealed that ALTB changed the secondary structure of HSA.

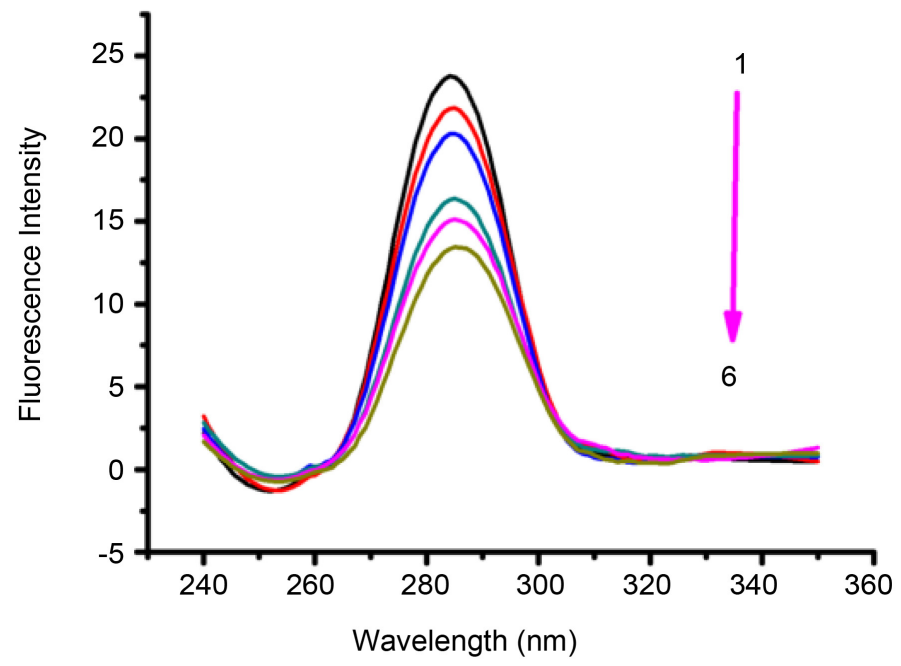

(A)

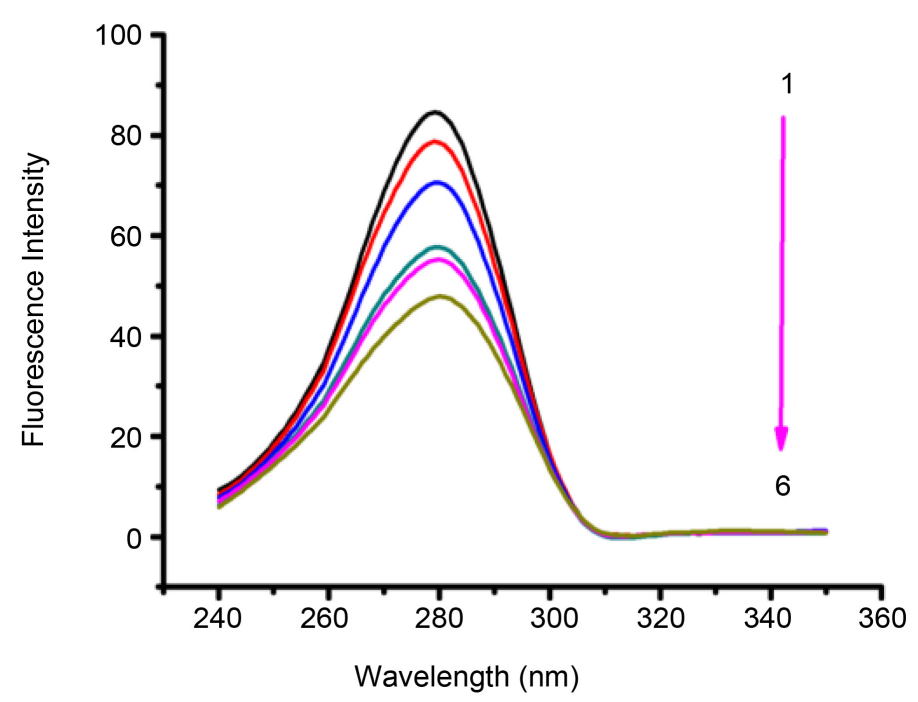

(B)

Figure 6. Synchronous fluorescence spectra of ALTB-HSA system. (1) $C_{(\mathrm{HSA})}=1 \times 10^{-6} \mathrm{~mol} / \mathrm{L},(2-6) C_{(\mathrm{ALTB})} / C_{(\mathrm{HSA})}=5,10,15,20,25 . T=$ $298 \mathrm{~K}, \mathrm{pH}=7.4$. (A) $\Delta \lambda=15 \mathrm{~nm}$, (B) $\Delta \lambda=60 \mathrm{~nm}$. 


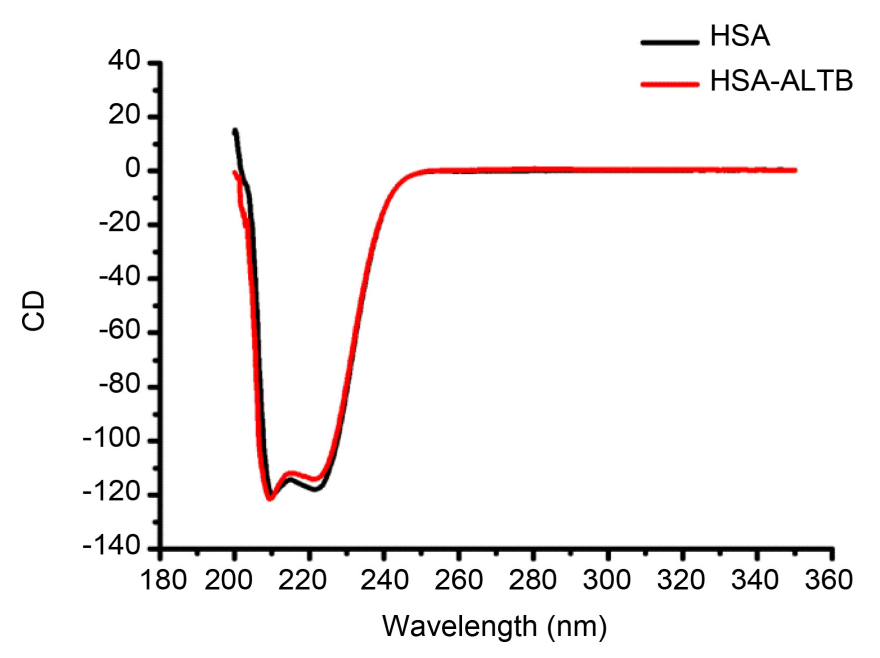

Figure 7. Circular dichroism spectra of ALTB-HSA system. $C_{(\mathrm{HSA})}=$ $1 \times 10^{-6} \mathrm{~mol} / \mathrm{L}, C_{\text {(АLTB })}=5 \times 10^{-6} \mathrm{~mol} / \mathrm{L}$.

\subsubsection{Three-Dimensional Fluorescence Spectra}

The three-dimensional fluorescence spectroscopy in Figure 8 was also used to illustrate conformational changes of HSA [35]. The three-dimensional fluorescence spectroscopy of HSA and ALTB-HSA were shown in Figure 8(a) and Figure $8(\mathrm{~b})$, respectively. Peak 1 was the characteristic peak of polypeptide skeleton, and peak 2 was that of Tyr and Trp residues [36] [37]. The values of maximum emission wavelength $\left(E_{m}\right)$ and excitation wavelength $\left(E_{x}\right)$ were shown in Table 3.

The stocks shifts were calculated by subtracting excitation wavelength from emission wavelength. The maximum fluorescence intensities of peak 1 and peak 2 both decreased and exhibited red shifts with the addition of ALTB, which can be observed in Table 3. The decrease of peak 1 indicated the changes of polypeptide skeleton in the presence of ALTB-HSA complex, which conformed to the increase of $\alpha$-helix in CD spectra [38]. The red shift of peak 2 suggested that ALTB increased the polarity and decreased the hydrophobicity around the Tyr and Trp of HSA [39]. It was consistent with the results of synchronous fluorescence.

In summary, ALTB helps to change the conformation of HSA according to the results presented in this section.

\subsection{Binding Sites Investigation}

\subsubsection{Molecular Docking}

HSA contains three homologous $\alpha$-helical domains (I, II and III), with two subdomains (A and B) of each. As is known to all, Trp 214 locates at the IIA subdomain of HSA [40] [41]. The molecule docking had been used to forecast the binding site of ALTB with HSA, and results of which were shown in Figure 9(a) and Figure 9(b). Based on Figure 9(a), the interaction site was mainly in the vicinity of IIA subdomain. And according to Figure 9(b), ALTB mainly interacted with Lys 351, Arg209, and Glu354 residues of HSA. 


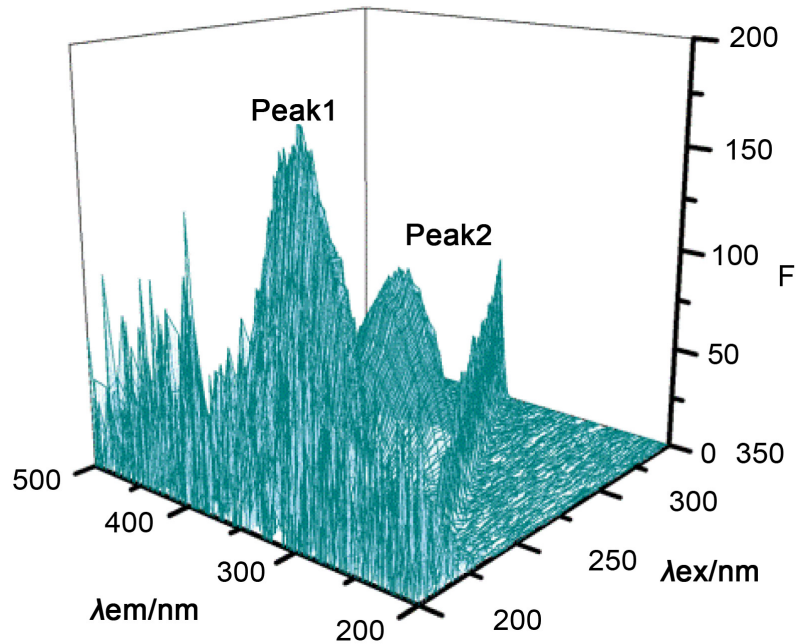

(A)

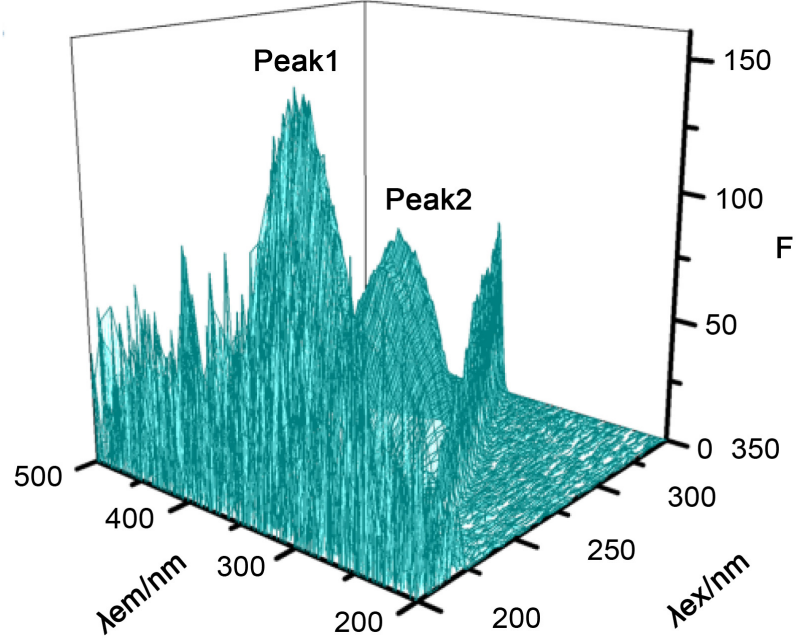

(B)

Figure 8. Three-dimensional fluorescence spectra of ALTB-HSA system. (A) $C_{(\mathrm{HSA})}=1 \times 10^{-6} \mathrm{~mol} / \mathrm{L}$, (B) $C_{(\mathrm{ALTB})} / C_{(\mathrm{HSA})}=5 . \mathrm{T}=$ $298 \mathrm{~K}, \mathrm{pH}=7.4$.

\subsubsection{Site-Selective Binding of ALTB on HSA}

The principal regions of interaction sites on HSA are located in the hydrophobic subdomains IIA and IIIA, which are denominated as Sudlow site I and site II Phenylbutazone and ibuprofen serve as the site markers to monitor Sudlow sites I and site II, respectively [42] [43]. In the following experiments, several sets of competitive experiments were carried out to identify the binding sites.

By keeping equimolar concentrations of site markers and HSA at $1.0 \times 10^{-6}$ $\mathrm{mol} / \mathrm{L}, \mathrm{ALTB}$ was gradually added into the system. The binding constants had been calculated and listed in Table 4 by scanning the fluorescence spectra. Results showed that the binding constant was significantly changed in the presence of phenylbutazone. However, the influence was indistinctive in the presence of ibuprofen. In this case, the binding site was mainly located within Sudlow sites I or IIA subdomain of HSA. 

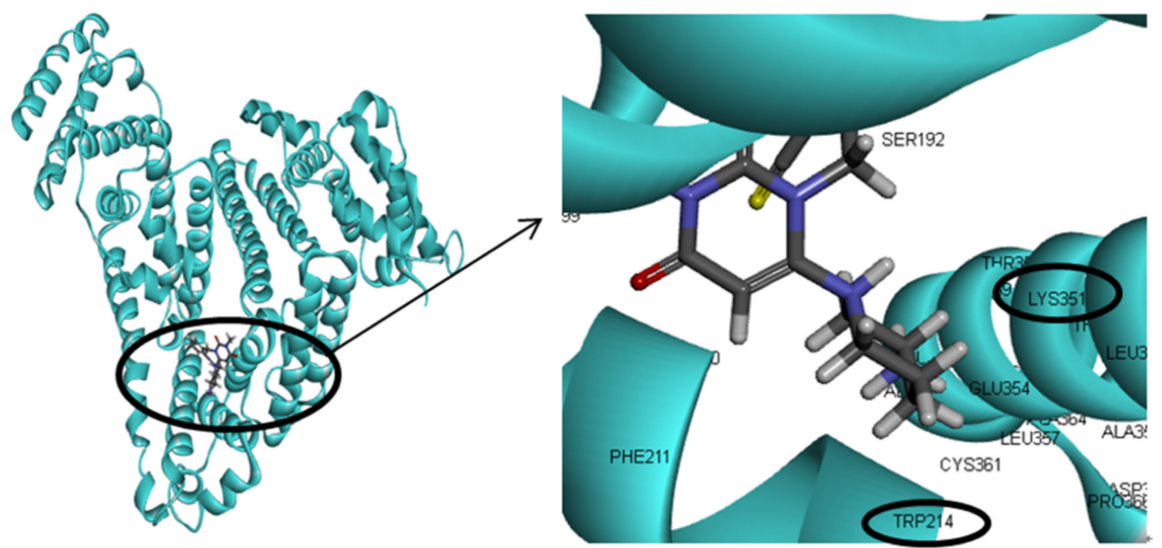

(A)

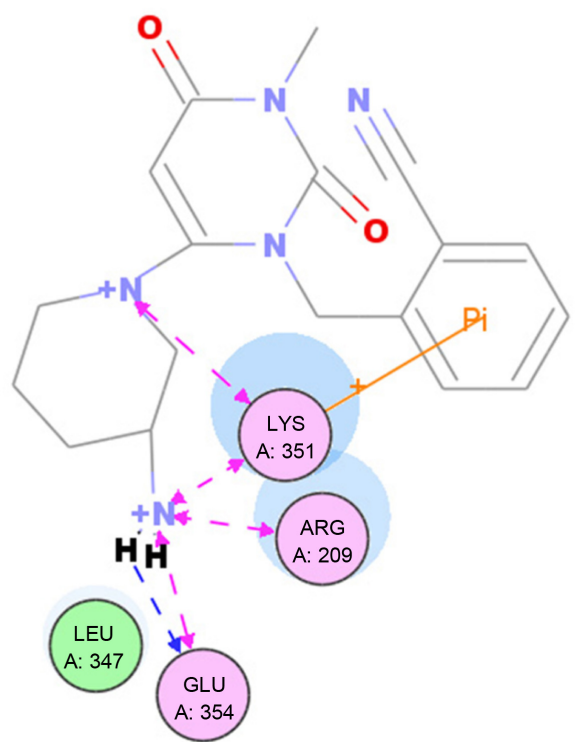

(B)

Figure 9. Interaction mode between ALTB and HAS.

Table 3. Peak values of three-dimensional fluorescence spectra of ALTB-HSA system.

\begin{tabular}{ccccc}
\hline & $E_{X}(\mathrm{~nm})$ & $E_{m}(\mathrm{~nm})$ & Stocks shift $(\mathrm{nm})$ & $F$ \\
\hline Peak1 (A) & 225 & 338 & 113 & 181 \\
Peak2 (A) & 280 & 335 & 55 & 96 \\
Peak1 (B) & 225 & 341 & 116 & 149 \\
Peak2 (B) & 280 & 343 & 63 & 89 \\
\hline
\end{tabular}

Table 4. Binding constants of competitive experiments of ALTB-HSA system.

\begin{tabular}{cccc}
\hline Site marker & $\boldsymbol{K}_{\mathrm{a}} /\left(\mathrm{L} \cdot \mathrm{mol}^{-1}\right)$ & $\boldsymbol{n}$ & $\boldsymbol{R}^{2}$ \\
\hline Blank & $4.81 \times 10^{6}$ & 1.49 & 0.9923 \\
Phenylbutazone & $1.10 \times 10^{5}$ & 1.12 & 0.9932 \\
Ibuprofen & $1.10 \times 10^{6}$ & 1.34 & 0.9930 \\
\hline
\end{tabular}




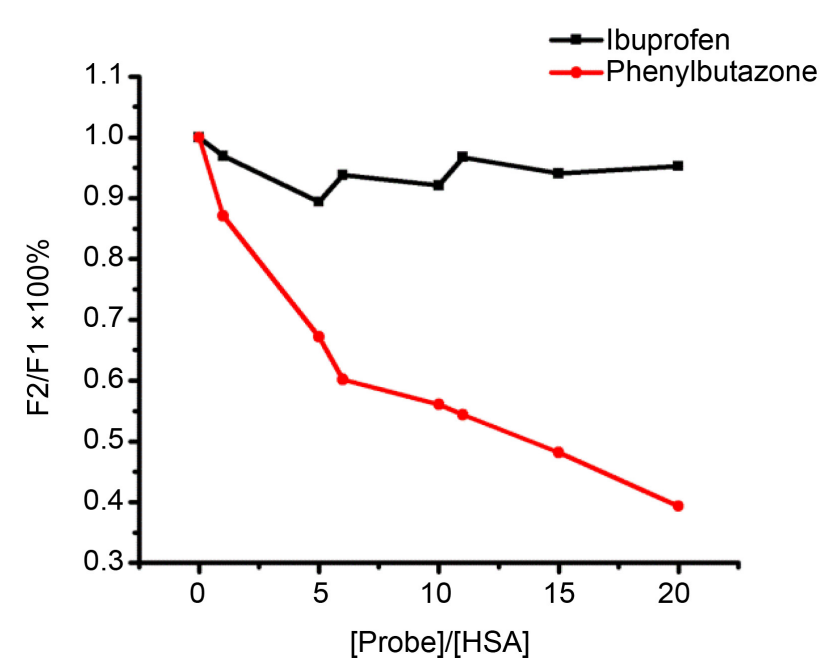

Figure 10. Effect of site markers on HSA-ALTB system.

In order to ensure a better minimal nonspecific binding of the site markers, the molar ratio of ALTB and HSA was fixed at 10:1. Site markers were gradually added to the reaction system. As shown in Figure 10, $F_{2}$ and $F_{1}$ are the fluorescence intensity in the presence and absence of probes, respectively. Compared with ibuprofen, the phenylbutazone affected the fluorescence intensity of reaction system more obviously. In the meantime, the binding site was mainly located within IIA subdomain of HSA. Based on Table 4 and Figure 10, it is concluded that the binding area is mainly located at Sudlow sites I, the IIA subdomain of HSA [44].

\section{Conclusion}

In this work, the interaction mechanism, the binding site and the conformational changes of HSA with ALTB were characterized by multi-spectral methods and molecule docking technique under physiological conditions. The fluorescent analysis results indicated that ALTB statically quenched the intrinsic fluorescence of HSA. The negative values of $\Delta H$ and $\Delta S$ revealed the presence of van der Waals forces and hydrogen bonding in the binding process. There was only one binding site of ALTB with HSA. Besides, the binding distance was obtained by spectral overlaps which demonstrated the presence of static quenching as well. The multi-spectral experimental results suggested that ALTB changed the conformation of HSA by forming the complex. It reduced the hydrophobicity and increased the polarity of HSA. The molecule docking and site marker competitive experiment indicated that binding site was bound at IIA subdomain of HSA. This work provided a reference for the distribution and transportation of ALTB in vivo, and was conducive to improving the pharmacokinetics and pharmacodynamics of ALTB.

\section{Acknowledgements}

This work was supported by the national natural science foundation of China 
[grant number 21303105].

\section{Conflicts of Interest}

The authors declare no conflicts of interest regarding the publication of this paper.

\section{References}

[1] Switzeny, O.J., Müllner, E., Wagner, K.H., Brath, H., Aumüller, E. and Haslberger, A.G. (2012) Vitamin and Antioxidant Rich Diet Increases MLH1 Promoter DNA Methylation in DMT2 Subjects. Clinical Epigenetics, 4, 19. https://doi.org/10.1186/1868-7083-4-19

[2] Huang, D.D., Shi, G., Jiang, Y., Yao, C. and Zhu, C. (2020) A Review on the Potential of Resveratrol in Prevention and Therapy of Diabetes and Diabetic Complications. Biomedicine \& Pharmacotherapy, 125, Article ID: 109767. https://doi.org/10.1016/j.biopha.2019.109767

[3] Athyros, V.G., Imprialos, K., Stavropoulos, K., Sahinidis, A. and Doumas, M. (2019) Understanding the Cardiovascular Risk with Non-Insulin Antidiabetic Drugs. EXpert Opinion on Drug Safety, 18, 241-251. https://doi.org/10.1080/14740338.2019.1586881

[4] Helsted, M.M., Gasbjerg, L.S., Lanng, A.R., Bergmann, N.C., Stensen, S., Hartmann, B., Christensen, M.B., Holst, J.J., Vilsbøll, T., Rosenkilde, M.M. and Knop, F.K. (2020) The Role of Endogenous GIP and GLP-1 in Postprandial Bone Homeostasis. Bone, 140, Article ID: 115553. https://doi.org/10.1016/j.bone.2020.115553

[5] Deacon, C.F. (2018) Peptide Degradation and the Role of DPP-4 Inhibitors in the Treatment of Type 2 Diabetes. Peptides, 100, 150-157. https://doi.org/10.1016/j.peptides.2017.10.011

[6] Nunhart, P., Konkol’ová, E., Janovec, L., Kašpárková, J., Malina, J., Brabec, V., Matejová, M., Miltáková, B., Novotny, L., Phillips, O.A., Udo, E. and Kozurkova, M. (2020) Antimicrobial Activity and DNA/HSA Interaction of Fluorinated 3,6,9-Trisubstituted Acridines. Chemical Papers, 74, 2327-2337. https://doi.org/10.1007/s11696-020-01079-4

[7] Chaves, O.A., Ferreira, R.C., da Silva, L.S., de Souza, B.C.E., Cesarin-Sobrinho, D., Netto-Ferreira, J.C., Sant'Anna, C.M.R. and Ferreira, A.B.B. (2018) Multiple Spectroscopic and Theoretical Approaches to Study the Interaction between HSA and the Antiparasitic Drugs: Benznidazole, Metronidazole, Nifurtimox and Megazol. Journal of the Brazilian Chemical Society, 29, 1551-1562. https://doi.org/10.21577/0103-5053.20180029

[8] Ma, J., Fan, Y., Si, Q., Liu, Y., Wang, X., Liu, H. and Xie, M. (2017) Interactions of Three Chalcones with Human Serum Albumin Revealed by Spectroscopic Techniques. Analytical Sciences, 33, 493-498. https://doi.org/10.2116/analsci.33.493

[9] Eraj, M.Z., Eriksson, L., Ramezani, M., Alibolandi, M., Babaei, M. and Saljooghi, A.S. (2021) Three Novel Complexes of Copper: Synthesis, Characterization, Crystal Structure, HSA-Binding and Docking Studies, and Antiproliferative Activity. Journal of the Iranian Chemical Society, 18, 765-783. https://doi.org/10.1007/s13738-020-02067-x

[10] Hekmat, A., Salavati, F. and Tackallou, S.H. (2020)The Effects of Paclitaxel in the Combination of Diamond Nanoparticles on the Structure of Human Serum Albumin (HSA) and Their Antiproliferative Role on MDA MB 231 Cells. The Protein Journal, 39, 268-283. https://doi.org/10.1007/s10930-020-09882-4 
[11] Nasir, Z., Shakir, M., Wahab, R., Shoeb, M., Alam, P., Khan, R.H., Mobin, M. and Lutfullah (2017) Co-Precipitation Synthesis and Characterization of Co Doped $\mathrm{SnO}_{2}$ NPs, HSA Interaction via Various Spectroscopic Techniques and Their Antimicrobial and Photocatalytic Activities. International Journal of Biological Macromolecules, 94, 554-565. https://doi.org/10.1016/j.ijbiomac.2016.10.057

[12] Mohammad, B. and Hossein, F.M. (2018) Fluorescence Spectroscopy, Molecular Docking and Molecular Dynamic Simulation Studies of HSA-Aflatoxin B1 and G1 Interactions. Journal of Luminescence, 202, 345-353.

https://doi.org/10.1016/j.jlumin.2018.05.066

[13] Zhou, Y., Song, T., Cao, Y., Gong, G., Zhang, Y., Zhao, H. and Zhao, G. (2018) Synthesis and Characterization of Planar Chiral Cyclopalladated Ferrocenylimines: DNA/HSA Interactions and in Vitro Cytotoxic Activity. Journal of Organometallic Chemistry, 871, 1-9. https://doi.org/10.1016/j.jorganchem.2018.06.027

[14] Wang, C., Wu, Q.H., Li, C.R., Wang, Z., Ma, J.J., Zang, X.H. and Qin, N.X. (2007) Interaction of Tetrandrine with Human Serum Albumin: A Fluorescence Quenching Study. Analytical Sciences, 23, 429-433. https://doi.org/10.2116/analsci.23.429

[15] Lakshmi, T.P., Mondal, M., Ramadas, K. and Natarajan, S. (2017) Molecular Interaction of 2,4-Diacetylphloroglucinol (DAPG) with Human Serum Albumin (HSA): The Spectroscopic, Calorimetric and Computational Investigation. Spectrochimica Acta Part A Molecular \& Biomolecular Spectroscopy, 183, 90-102. https://doi.org/10.1016/j.saa.2017.04.012

[16] Tanzadehpanah, H., Mahaki, H., Moghadam, N.H., Salehzadeh, S., Rajabi, O., Najafi, R., Amini, R. and Saidijam, M. (2019) Binding Site Identification of Anticancer Drug Gefitinib to HSA and DNA in the Presence of Five Different Probes. Journal of Biomolecular Structure and Dynamics, 37, 823-836.

https://doi.org/10.1080/07391102.2018.1441073

[17] Parray, M.U.D., Mir, M.U.H., Dohare, N., Maurya, N., Khan, A.B., Borse, M.S. and Patel, R. (2018) Effect of Cationic Gemini Surfactant and Its Monomeric Counterpart on the Conformational Stability and Esterase Activity of Human Serum Albumin. Journal of Molecular Liquids, 260, 65-77. https://doi.org/10.1016/j.molliq.2018.03.070

[18] Wu, D., Liu, D., Zhang, Y. and Li, H. (2018) Unravelling the Binding Mechanism of Benproperine with Human Serum Albumin: A Docking, Fluorometric, and Thermodynamic Approach. European Journal of Medicinal Chemistry, 146, 245-250. https://doi.org/10.1016/j.ejmech.2018.01.064

[19] Maji, A., Beg, M., Das, S., Sahoo, N.K., Jha, P.K., Islam, M.M. and Hossain, M. (2019) Binding Interaction Study on Human Serum Albumin with Bactericidal Gold Nanoparticles Synthesized from a Leaf Extract of Musa balbisiana: A Multispectroscopic Approach. Luminescence the Journal of Biological \& Chemical Luminescence, 34, 563-575. https://doi.org/10.1002/bio.3639

[20] Bi, S., Zhao, T., Zhou, H., Wang, Y. and Li, Z. (2016) Probing the Interactions of Bromchlorbuterol-HCl and Phenylethanolamine A with HSA by Multi-Spectroscopic and Molecular Docking Technique. The Journal of Chemical Thermodynamics, 97, 113-121. https://doi.org/10.1016/j.jct.2016.01.004

[21] Poureshghi, F., Ghandforoushan, P., Safarnejad, A. amd Soltani, S. (2017) Interaction of an Antiepileptic Drug, Lamotrigine with Human Serum Albumin (HSA): Application of Spectroscopic Techniques and Molecular Modeling Methods. Journal of Photochemistry \& Photobiology, B: Biology, 166, 187-192. https://doi.org/10.1016/j.jphotobiol.2016.09.046

[22] Cui, Y., Hao, E., Hui, G., Guo, W. and Cui, F. (2013) Investigations on the Interac- 
tions of Diclofenac Sodium with HSA and ctDNA Using Molecular Modeling and Multispectroscopic Methods. Spectrochimica Acta Part A: Molecular and Biomolecular Spectroscopy, 110, 92-99. https://doi.org/10.1016/j.saa.2013.01.093

[23] Byadagi, K., Meti, M., Nandibewoor, S. and Chimatadar, S. (2017) Investigation of Binding Behaviour of Procainamide Hydrochloride with Human Serum Albumin Using Synchronous, 3D Fluorescence and Circular Dichroism. Journal of Pharmaceutical Analysis, 7, 103-109. https://doi.org/10.1016/j.jpha.2016.07.004

[24] Zhu, M., Wang, L.J., Wang, Y., Zhou, J., Ding, J., Li, W., Xin, Y., Fan, S., Wang, Z. and Wang, Y. (2018) Biointeractions of Herbicide Atrazine with Human Serum Albumin: UV-Vis, Fluorescence and Circular Dichroism Approaches. International Journal of Environmental Studies and Public Health, 15, 116.

https://doi.org/10.3390/ijerph15010116

[25] Niladri, B., Ankur, C., Sibani, C. and Chirantan Roy, C. (2018) Example of Square Planar Copper(II) Biuret Complex: Crystal Structure, DNA and Protein Binding Activity and Molecular Docking Study. Inorganic \& Nano Metal Chemistry, 48, 495-507. https://doi.org/10.1080/24701556.2019.1572623

[26] Nahid, S., Shokoufeh, H., Avat, T. and Fariba, M. (2018) Synthesis, Characterization, HSA Interaction, and Antibacterial Activity of a New Water-Soluble Pt(II) Complex Containing the Drug Cephalexin. Journal of Coordination Chemistry, 71, 3708-3730. https://doi.org/10.1080/00958972.2018.1525488

[27] Sun, Q., Gan, N., Zhang, S., Zhao, L.,Tang, P., Pu, H., Zhai, Y., Gan, R. and Li, H. (2019) Insights into Protein Recognition for $\gamma$-Lactone Essences and the Effect of Side Chains on Interaction via Microscopic, Spectroscopic, and Simulative Technologies. Food Chemistry, 278, 127-135.

https://doi.org/10.1016/j.foodchem.2018.11.037

[28] Xue, Z., Cheng, A., Li, Y., Yu, W. and Kou, X. (2017) Investigating Interaction between Biochanin A and Human Serum Albumin by Multi-Spectroscopic and Molecular Simulation Methods. Transactions of Tianjin University, 23, 325-333. https://doi.org/10.1007/s12209-017-0046-1

[29] Ariga, G.G., Naik, P.N., Chimatadar, S.A. and Nandibewoor, S.T. (2017) Interactions between Epinastine and Human Serum Albumin: Investigation by Fluorescence, UV-Vis, FT-IR, CD, Lifetime Measurement and Molecular Docking. Journal of Molecular Structure, 1137, 485-494.

https://doi.org/10.1016/j.molstruc.2016.12.066

[30] Cui, F., Zhang, Q., Yao, X., Luo, H., Yang, Y., Qin, L., Qu, G. and Lu, Y. (2008) The Investigation of the Interaction between 5-Iodouracil and Human Serum Albumin by Spectroscopic and Modeling Methods and Determination of Protein by Synchronous Fluorescence Technique. Pesticide Biochemistry and Physiology, 90, 126134. https://doi.org/10.1016/j.pestbp.2007.11.002

[31] Zhang, M., Chai, Y. and Han, B. (2019) Mechanistic and Conformational Studies on the Interaction between Myriocin and Human Serum Albumin by Fluorescence Spectroscopy and Molecular Docking. Journal of Solution Chemistry, 48, 835-848. https://doi.org/10.1007/s10953-019-00895-X

[32] Chen, Z.F., Zhang, S.P. and Zhang, J. (2015) Affinity of a Mononuclear Monofunctional Anticancer Pt(II) Complex to Human Serum Albumin: A Spectroscopic Approach. Biometals, 28, 1031-1041. https://doi.org/10.1007/s10534-015-9888-y

[33] Murugesana, A., Singh, T., Rajamanikandan, R., Vinu, M., Ilanchelian, M., Line, C.H. and Gengan, R.M. (2021) Synthesis, Spectroscopic, DFT, HSA Binding and Docking Studies of New

1,5-bis(4-chlorophenyl)-3-(2-(4-methylpiperazin-1-yl)quinolin-3-yl)pentane-1,5-di 
one. Journal of Molecular Structure, 1223, Article ID: 129260. https://doi.org/10.1016/j.molstruc.2020.129260

[34] Mir, M.U.H., Maurya, J.K., Ali, S., Ubaid-ullah, S., Khan, A.B. and Patel, R. (2014) Molecular Interaction of Cationic Gemini Surfactant with Bovine Serum Albumin: A Spectroscopic and Molecular Docking Study. Process Biochemistry, 49, 623-630. https://doi.org/10.1016/j.procbio.2014.01.020

[35] Xu, L., Hu, Y.X., Li, Y.C., Liu, Y.F., Zhang, L., Ai, H.X. and Liu, H.S. (2017) Study on the Interaction of Paeoniflorin with Human Serum Albumin (HSA) by Spectroscopic and Molecular Docking Techniques. Chemistry Central Journal, 11, 116. https://doi.org/10.1186/s13065-017-0348-3

[36] He, J., Yang, H., Li, S., Xu, K., Wang, Q., Huang, Y. and Li, H. (2016) Characterization of the Interaction between Acotiamide Hydrochloride and Human Serum Albumin: 1H STD NMR Spectroscopy, Electrochemical Measurement, and Docking Investigations. Rsc Advances, 6, 61109-61118. https://doi.org/10.1039/C6RA08310B

[37] Lu, Z., Qi, L., Li, G.X., Li, Q., Sun, G.H. and Xie, R.Z. (2014) In Vitro Characterization for Human Serum Albumin Binding Sorafenib, A Multi Kinase Inhibitor: Spectroscopic Study. Journal of Solution Chemistry, 43, 2010-2025.

https://doi.org/10.1007/s10953-014-0256-2

[38] Gan, Q., Fu, X., Chen, W., Xiong, Y., Fu, Y., Chen, S. and Le, X. (2016) Synthesis, DNA/HSA Interaction Spectroscopic Studies and in Vitro Cytotoxicity of a New Mixed Ligand $\mathrm{Cu}$ (II) Complex. Journal of Fluorescence, 26, 905-918. https://doi.org/10.1007/s10895-016-1779-2

[39] Tu, B., Wang, Y., Mi, R., Ouyang, Y. and Hu, Y.J. (2015) Evaluation of the Interaction between Naringenin and Human Serum Albumin: Insights from Fluorescence Spectroscopy, Electrochemical Measurement and Molecular Docking. Spectrochimica Acta Part A Molecular \& Biomolecular Spectroscopy, 149, 536-543. https://doi.org/10.1016/j.saa.2015.04.087

[40] Ascenzi, P. and Fasano, M. (2010) Allostery in a Monomeric Protein: The Case of Human Serum Albumin. Biophysical Chemistry, 148, 16-22. https://doi.org/10.1016/j.bpc.2010.03.001

[41] Rastegari, B., Karbalaei-Heidari, H.R., Yousefi, R., Zeinali, S. and Nabavizadeh, M. (2016) Interaction of Prodigiosin with HSA and $\beta$-Lg: Spectroscopic and Molecular Docking Studies. Bioorganic \& Medicinal Chemistry, 24, 1504-1512. https://doi.org/10.1016/j.bmc.2016.02.020

[42] Li, M.Y., Xiao, C.Q., Xu, Z.Q., Yin, M.M., Yang, Q.Q., Yin, Y.L. and Liu, Y. (2018) Role of Surface Charge on the Interaction between Carbon Nanodots and Human Serum Albumin. Spectrochimica Acta Part A: Molecular and Biomolecular Spectroscopy, 204, 484-494. https://doi.org/10.1016/j.saa.2018.06.082

[43] Nerusu, A., Chinthapalli, D.K. and Subramanyam, R. (2019) Role of Herborn (K240E) and Milano Slow (D375H) Human Serum Albumin Variants towards Binding of Phenylbutazone and Ibuprofen. International Journal of Biological Macromolecules, 134, 645-652. https://doi.org/10.1016/j.ijbiomac.2019.05.075

[44] Tan, H., Chen, L., Ma, L., Liu, S., Zhou, H., Zhang, Y., Guo, T., Liu, W., Dai, H. and Yu, Y. (2019) Fluorescence Spectroscopic Investigation of Competitive Interactions between Quercetin and Aflatoxin B1 for Binding to Human Serum Albumin. Toxins, 11, 214. https://doi.org/10.3390/toxins11040214 